\title{
ЧЕЛОВЕЧЕСКИЙ ФАКТОР
}

А. М. Лушкин

\section{ТЕХНОЛОГИЯ АВТОМАТИЗИРОВАННОЙ ПРОГНОСТИЧЕСКОЙ РИСКОМЕТРИИ ФУНКЦИОНАЛЬНОЙ НАДЁЖНОСТИ ПИЛОТА}

\begin{abstract}
Аннотация. Предметом исследования являются вопросы учета человеческого фактора при реализации управления функиионированием сложных эргатических (человеко-мачинных) систем при наличии малого (недостаточного для статистического прогнозирования) объема информации о нештатных (аварийных) ситуациях, обусловленных человеческим фактором, а также предпосылок к развитию таких ситуаций. То есть, решается задача оиенивания вероятности события, не наблюдавщегося за исследуемый период, имеющая важное значение для обеспечения превентивного управления эргатической системой с четом характеристикчеловеческого фактора. Методология исследования основана на теории функииональных состояний операторов систем "человекмашина", теории вероятностей, математической статистике. Новизна исследования заключается в разработке технологии прогностического оценивания функциональной надёжности пилота по оценке вероятности выхода пилотажных параметров за эксплуатационные ограничения в полете, реализованной в автоматизированной системе управления рисками безопасности полетов. Полученные результаты имеют общий характер, позволяющий применить их для адаптивного управления функиионированием любых эргатических систем.
\end{abstract}

Ключевые слова: учет человеческого фактора, управление эргатической системой, функииональная надежность человека, концепция приемлемого риска, управление состоянием системы, статистическое прогнозирование, учет эксплуатационных ограничений, надежность эргатической системы, превентивное управление рисками, мониторинг безопасности.

\section{Введение}

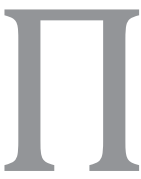
ризнание на международном уровне концепции приемлемого риска авиационного происшествия в полете способствует достижению максимальной коммерческой эффективности летной эксплуатации воздушного транспорта, но обостряет проблему обеспечения требуемого уровня безопасности полетов (БП) [1-5]. В разряд нерешаемых переходит задача подготовки пилотов соответствующего профессионального уровня, выполняющих полеты с соответствующей функциональной надежностью, при одновременном снижении времени и затрат, связанных с обучением, вводом в строй, профессиональным ростом, в том числе при допуске к полетам на новых типах воздушных судов (BC), при назначении командирами ВC, инструкторами и др. [6-9]. Отмеченная проблема усугубляется накоплением усталости экипажей в периоды интенсивной летной работы, когда налет у основной части пилотов приближается к ограничению по санитарным правилам и нормам [8-14].

В той или иной степени успешное решение коммерческих задач периодически вступает в противоречие с обеспечением требуемого уровня БП, поскольку увеличивается риск авиационного события, причиной которого является недостаточно высокое качество пилотирования вследствие сниженной функциональной надежности профессиональной деятельности летчика [12-17]. Снижение качества пилотирования обусловливает увеличение частоты случаев выхода пилотажных параметров за эксплуатационные ограничения BC. В свою очередь, выход показателей за эксплуатационные ограничения в полете классифицируется как авиационное событие, подлежащее расследованию: инцидент, серьезный инцидент 


\section{Человеческий фактор}

или авиационное происшествие (в зависимости от тяжести последствий) [18]. Эксплуатационные ограничения оговариваются Руководством по летной эксплуатации (РЛЭ) типа ВС и охватывают ряд пилотажных параметров, регистрируемых бортовыми средствами регистрации полетных данных (БСРПД): скорость, перегрузка, режимы работы силовых установок, углы крена, тангажа, атаки и др.

\section{Постановка задачи прогностической рискометрии функциональной надежности пилота}

Обычно при принятии решения, связанного с определением профессионального уровня пилота, преобладает субъективная оценка степени готовности пилота к выполнению самостоятельных полетов (или к инструкторской работе). Но функциональные возможности современных БСРПД, средств наземной обработки полетной информации (ПИ), их математическое обеспечение, в том числе экпресс-анализ, способствуют не только оперативности, но и объективности индивидуального оценивания качества пилотирования в каждом отдельно взятом полете. Очевидно, что достигнутый профессиональный уровень летчика должен определяться по некоторой совокупности выполненных полетов, отличающихся, как правило, степенью сложности, а, следовательно, и степенью потенциальной успешности. Должна вестись и максимально использоваться управляемая база данных (БД) ПИ.

При творческом подходе к использованию такой ПИ появляется возможность анализа накапливаемой информации в интересах объективной количественной оценки риска авиационного события, обусловленного выходом пилотажных параметров за эксплуатационные ограничения. Под оценкой риска понимается вероятностная мера наступления авиационного события фиксированной степени тяжести (например, авиационного инцидента), вследствие превышения эксплуатационных ограничений ВС.

Пилотажные параметры, на которые распространяются эксплуатационные ограничения, в обязательном порядке регистрируются в накопителях БСРПД. В настоящее время ПИ практически всех полетов подлежит обработке и анализу. Таким образом, теоретически представляется возможным применительно к каждому командиру экипажа или пилотировавшему летчику, по совокупности выделенных из ПИ экстремальных значений контролируемых пилотажных параметров, оценить вероятность выхода за эксплуатационные ограничения в полете, то есть вероятность авиационного события типа «инцидент», даже если таких фактов за оцениваемый период летной работы не наблюдалось.

Достижение ограничиваемым параметром $X$ некоторого (заведомо установленного для конкретного типа ВC) значения $X_{\text {огр }}$ можно рассматривать как реализацию случайного процесса, описываемого функцией $X(t)$, а совокупность экстремальных значений ограничиваемого показателя $\left\{X_{E X T R}\right\}$, имевших место в каждом полете анализируемого периода летной работы, можно рассматривать как случайные величины. По совокупности значений $\left\{X_{E X T R}\right\}$ можно оценивать вероятность выхода показателей полета за эксплуатационные ограничения.

Оценка вероятности выхода случайной функции экстремальных значений контролируемого параметра за предел некоторого значения $X_{\text {огр }}$ расположенного в непосредственной близости среднестатистического значения $X_{E X T R c p .}$ наблюдаемой совокупности $\left\{X_{E X T R}\right\}$, не представляет сложности при любом законе распределения [19-24]. Но значение эксплуатационного ограничения параметра и центр распределения его наблюдаемых экстремальных значений обычно оказываются удаленными друг от друга более, чем на $3 \sigma(x)(\sigma(x)$ - оценка среднего квадратичного (стандартного) отклонения). На практике определить функцию распределения случайной величины за пределами $m(x) \pm 3 \sigma(x)(m(x)$ - оценка математического ожидания случайной величины $x$ ) не удается по причине отсутствия необходимого объема исходных статистических данных. Таким образом, актуальной является задача оценивания вероятности события, как правило, не наблюдавшегося за исследуемый период.

\section{Особенности плотности распределения экстремальных значений контролируемого пилотажного параметра}

Решение сформулированной задачи усложняется еще и тем, что, вид функции распределения случайной величины за пределами $m(x) \pm 3 \sigma(x)$ 


\section{Тренды и управление 1(9) • 2015}

практически не зависит от вида этой функции в окрестности математического ожидания (в центре распределения). Этим подтверждается потребность и должна обеспечиваться возможность выбора универсального вида функции распределения с определением параметров распределения непосредственно по имеющимся результатам наблюдений.

На рис.1 приведен пример распределения экстремальных значений характерного пилотажного параметра у трех пилотов, отличающихся удалением оценки математического ожидания наблюдений показателя от установленного ограничения $\left(m_{3}(x)>m_{2}(x)>m_{1}(x)\right)$ и оценкой стандартного отклонения наблюдений $\left(\sigma_{1}=\sigma_{3} ; \sigma_{2}>\sigma_{1}, \sigma_{3}\right)$.

Из примера видно, что математическое ожидание экстремальных значений характерного параметра $X$ у третьего пилота значительно ближе к $X_{\text {огр }}$, чем у первого и второго, однако наивысшая вероятность выхода за $X_{\text {огр }}$ - у второго пилота, из-за большой дисперсии, то есть нестабильности, которую можно объяснить, к примеру, зависимостью $f(X)$ как от качества пилотирования, так и от условий полета: в нормальных условиях - высокое качество, но при любом усложнении условий полета качество пилотирования резко снижается вплоть до возможного выхода за эксплуатационные ограничения.

\section{Технология расчёта вероятности выхода контролируемого пилотажного параметра за установленные ограничения}

Пусть по результатам оцениваемых полетов некоторого летчика $A$ имеем совокупность из $n$ экстремальных значений характерного параметра $X$ в $n$ полетах. Представим их в виде вариационного ряда возрастающих значений:

$$
X_{E X T R .1}<X_{E X T R .2}<\ldots<X_{E X T R . i}<\ldots X_{E X T R . n}
$$

Оценим статистическую вероятность $\hat{P}_{i}\left(X_{E X T R}\right)$ (накопленную частоту непревышения всеми членами ряда $\left\{X_{E X T R . i}\right\}$ значения $X_{i}$ по формуле $\hat{P}_{i}\left(X_{\text {EXTR.i }}\right)=\frac{i}{n+1}$ :

$$
\hat{P}_{1}<\hat{P}_{2}<\ldots<\hat{P}_{i}<\ldots<\hat{P}_{n^{*}}
$$

Точки $\left(X_{E X T R . i}, \hat{P}_{i}\right)$ принадлежат функции распределения $\hat{P}\left(X_{E X T R}\right)$ (рис.2).

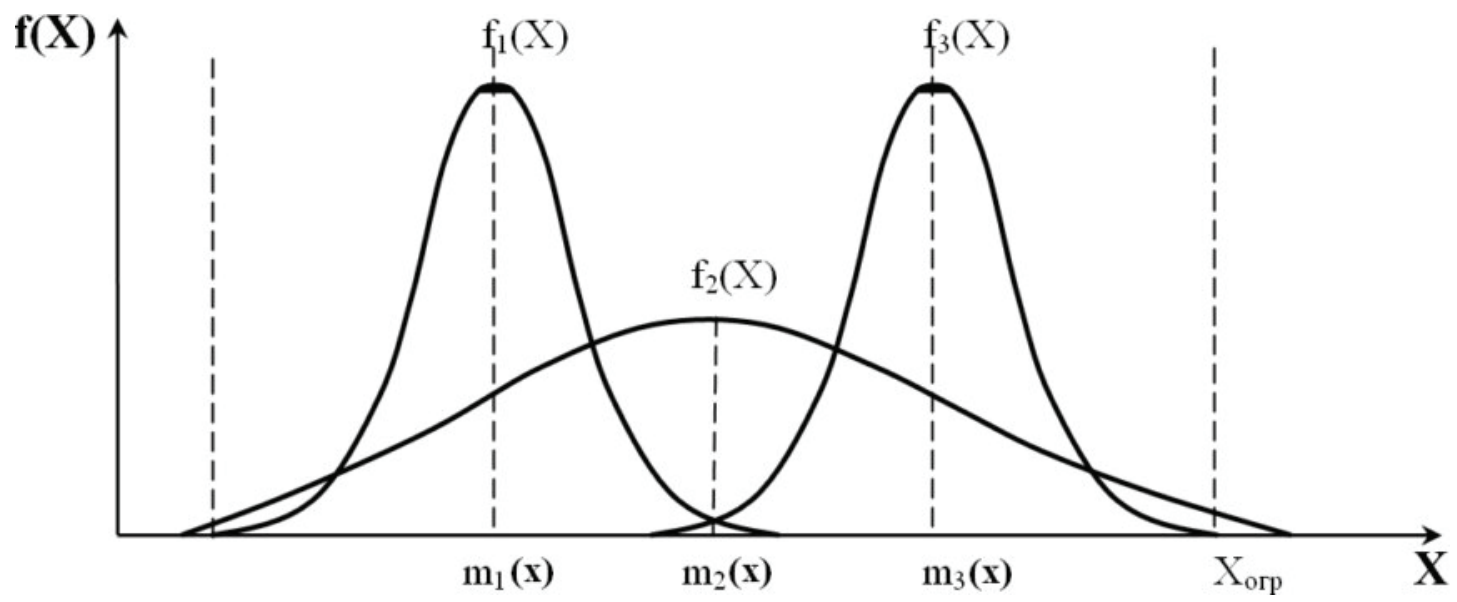

Рисунок 1. - Типовые плотности распределения экстремальных значений контролируемого пилотажного параметра. 


\section{Человеческий фактор}

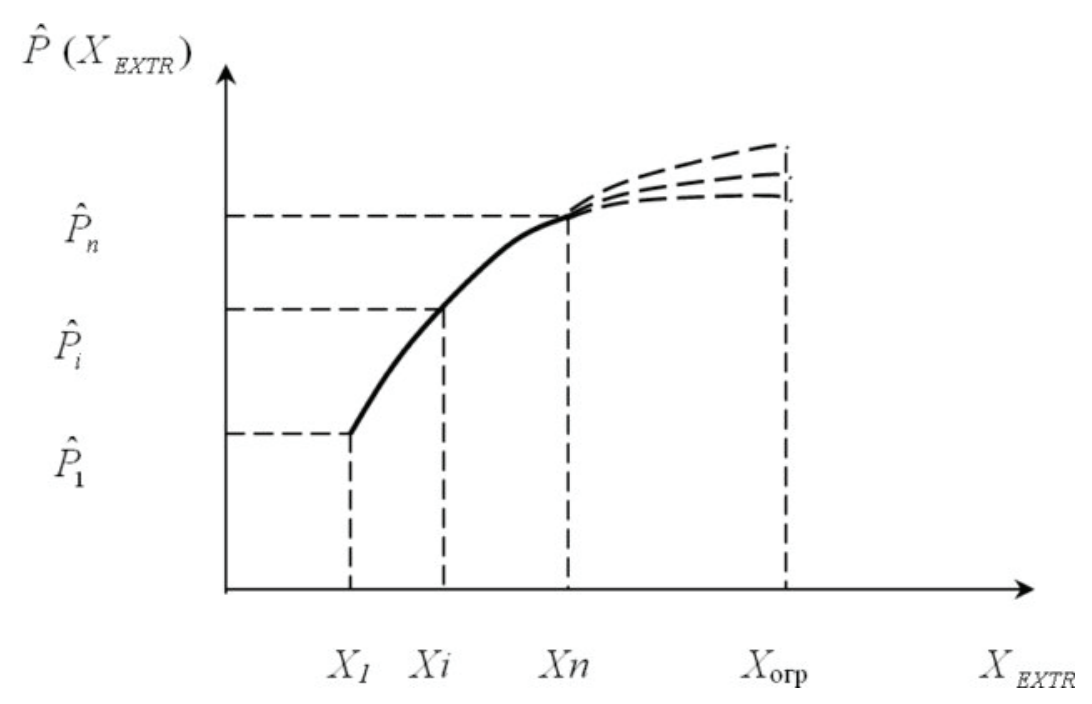

Рисунок 2. - Функция распределения экстремальных значений характерного пилотажного параметра.

Продление функции распределения $\hat{P}\left(X_{E X T R}\right)$ за точку $\left(X_{E X T R . n}, \hat{P}_{n}\right)$ до пересечения с вертикалью $X_{\text {огр }}$ позволило бы получить искомую оценку вероятности непревышения установленного эксплуатационного ограничения, т.е. получить значение функции $\hat{P}\left(X_{E X T R . o г p}\right)$. Но независимо от способа восстановления или экстраполяции функции $\hat{P}\left(X_{E X T R}\right)$ однозначную функцию распределения на интервале $\left[X_{n^{\prime}} X_{\text {огр. }}\right]$ получить невозможно в силу высокой степени неопределенности, что и отражено на рис. 2 размножением возможных вариантов в некоторой точке бифуркации $\left(X_{E X T R . n}, \hat{P}_{n}\right)$.

В тех случаях, когда экстремальные значения характерного параметра $X$ в разных реализациях (наблюдениях) не зависят друг от друга (как правило, это разные полеты или разные этапы полета), а случайная величина $X$ не ограничена ни справа, ни слева, закон ее распределения описывается функцией [21-24]:

$$
P\left(X_{\text {EXTR }}\right)=p\left(X_{\text {EXTR }}<X_{\text {EXTR.i }}\right)=\exp \left(-e^{-Y}\right),
$$

где $p\left(X_{E X T R}<X_{E X T R . i}\right)$ - вероятность непревышения независимой переменной $X_{E X T R}$ значения $X_{\text {EXTR.i }}$

$Y$ - линейная функция переменной $X_{E X T R}$ с неизвестными параметрами (нормированное отклонение).
Из записанной формулы следует связь нормированного отклонения $Y$ с аргументом $X_{E X T R}$ через статистическую вероятность $\hat{P}\left(X_{E X T R}\right)$ :

$$
Y=-\ln \left[-\ln \hat{P}\left(X_{E X T R}\right)\right] .
$$

В ко о рд и н а та а $\left(X_{E X T R}, Y\right), \quad$ т. е . $\left(X_{\text {EXTR }},\left\{-\ln \left[-\ln \hat{P}\left(X_{\text {EXTR }}\right)\right]\right\}\right)$ точки $\left(X_{\text {EXTR.i }}, Y_{i}\right)$ располагаются не на прервавшейся экспоненте, а на прямой линии (рис.3), экстраполяция которой

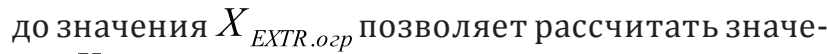
ние $Y_{\text {ОГР }}$, а по нему - оценку вероятности невыхода за эксплуатационные ограничения, используя формальное представление закона распределения случайной величины $X$ :

$$
p\left(X_{E X T R}<X_{\text {oгp }}\right)=\exp \left(-e^{-Y_{\text {OIP }}}\right) .
$$

Соответственно, вероятность выхода параметра $X$ за эксплуатационные ограничения определяется как:

$$
q_{\text {огр }}=1-p\left(X_{\text {EXTR }}<X_{\text {огр }}\right) .
$$

Достоверность оценки вероятности выхода пилотажных параметров за эксплуатационные ограничения зависит от дисперсии параметра (переменной $X_{E X T R}$ ) и количества наблюдений (оцениваемых полетов) [24]. Практика показала, 


\section{Тренды и управление 1(9) • 2015}

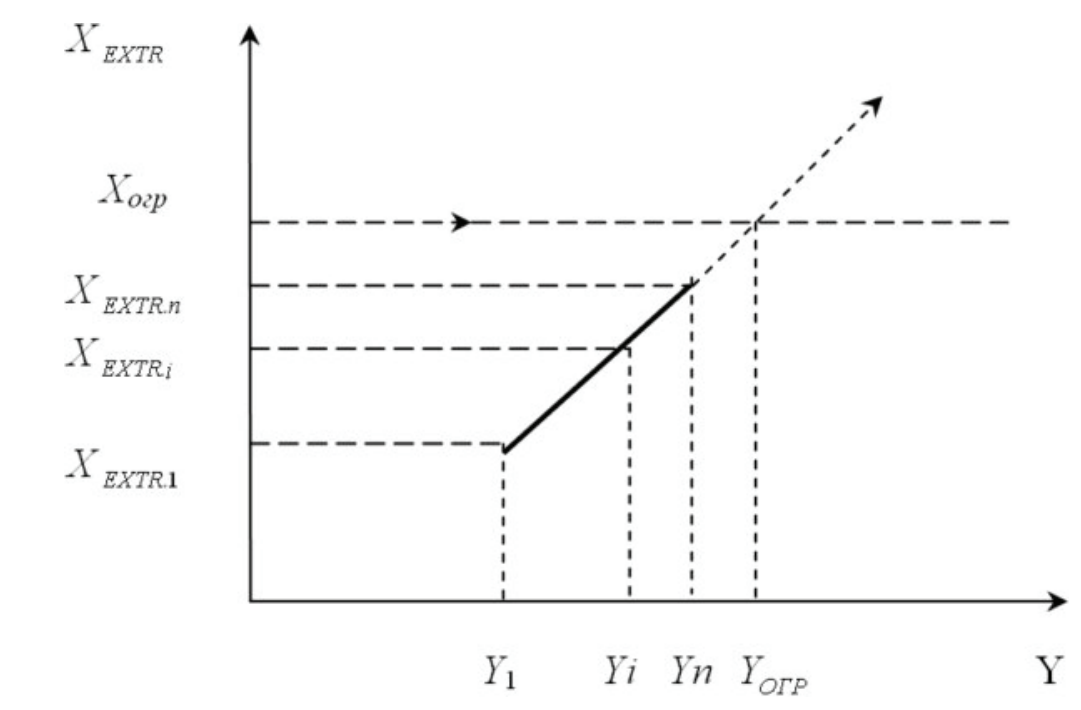

Рисунок 3. - График функции $X_{\text {EХTR }}=F(Y)$, где $Y=-\ln \left[-\ln \hat{P}\left(X_{E X T R}\right)\right]$.

что для получения приемлемой достоверности (при доверительной вероятности 0,8 ) обычно требуется информация не менее пяти выполненных полетов.

Если общее количество параметров полета, имеющих эксплуатационные ограничения на конкретном типе ЛА и регистрируемых в полете, равно $m$, то вероятность выхода за эксплуатационные ограничения (по любому параметру) в предстоящем полете составляет

$$
Q_{\Sigma}=1-\prod_{j=1}^{m} p_{j}
$$

\section{Множество наиболее важных пилотажных параметров, имеющих эксплуатационные ограничения}

При практической реализации стратегии превентивного управления уровнем БП в авиакомпании [25] методом экспертных оценок к характерным показателям, имеющим эксплуатационные ограничения и в наибольшей степени влияющим на БП в гражданской авиации, отнесены:

- $\quad$ вертикальная перегрузка $\left(n_{y}\right)$ на посадке;

- $\quad$ угол крена $(\gamma)$;

- $\quad$ угол тангажа на взлете $\left(v_{\text {взл }}\right)$;

- угол тангажа на посадке $\left(v_{n o c}\right)$.

Целесообразность использования вероятностного подхода к оцениванию редких событий, обусловленных выходом параметров полета за пределы эксплуатационных ограничений, подтверждается статистикой: за каждый рейс пилоты совершают в среднем 1,84 ошибки, в то время как максимальное количество ошибок на этапе полета - 14 [26]. Это свидетельствует о значительной разнице между среднестатистическим значением количественного показателя и его экстремальным значением.

\section{Пример реализации предложенной технологии}

В качестве примера, демонстрирующего возможности вышеизложенного подхода, на рис. 4 приведена динамика вероятности грубой посадки (превышение эксплуатационного ограничения $\left.n_{y}=2\right)$ у командира ВС Boeing 737, совершившего грубую посадку $\left(n_{y}=2,18\right)$ в июле 2009.

Из рис. 4 видно, что увеличение вероятности грубой посадки $q$ могло быть спрогнозировано в мае, за 2 месяца до инцидента, по тенденции ежемесячного линейного роста функции $\lg q$. T.e. вероятность грубой посадки у данного командира BC увеличивалась на два порядка (в 100 раз!) ежемесячно. Однако корректирующие меры не были предприняты. В результате в одном из полетов в июле вертикальная перегрузка на посадке составила $n_{y}=2,18$, т.е. было превышено установленное в 


\section{Человеческий фактор}

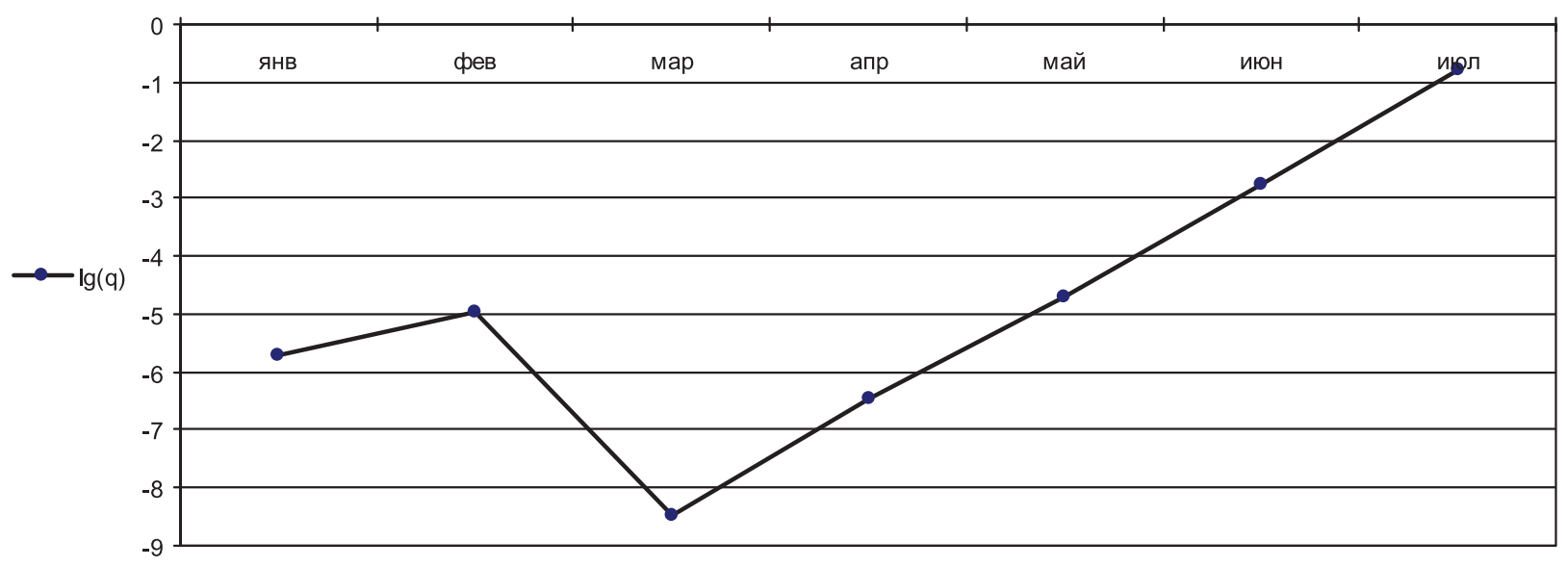

Рисунок 4. - Динамика оценки вероятности грубой посадки для командира Boeing 737.

РЛЭ Воeing 737 ограничение $n_{\text {уогр }}=2$. Оценка вероятности грубой посадки в июле составила 0,3 .

\section{Особенности автоматизированной системы управления рисками при производстве полетов}

В связи с трудоемкостью расчетов, требующих от аналитика соответствующего уровня математических знаний, описанная процедура расчета оценки вероятности не имевших место авиационных событий, обусловленных выходом параметров полета за эксплуатационные ограничения, формализована и положена в основу математического обеспечения Автоматизированной системы управления рисками при производстве полетов (АС УРПП), разработанной в авиакомпании «Трансаэро» в 2009 году [27, 28]. АС УРПП позволяет с любой периодичностью, например, ежемесячно, количественно оценивать функциональную надежность каждого пилота с учетом типа ВC, особенностей аэродрома вылета и посадки, в заданном временном интервале (количестве вылетов) и по другим исходным данным. Вычисления могут производиться по всей совокупности или по любому из контролируемых пилотажных параметров. Благодаря внедрению АС УРПП, в авиакомпании ведется ежемесячный мониторинг уровня функциональной надежности всех пилотирующих летчиков.
При освоении новых регулярных линий и новых аэродромов АС УРПП позволяет, начиная с пяти выполненных полетов, оценить вероятность выхода за эксплуатационные ограничения при взлете и посадке на любом из аэродромов. Поскольку динамичное развитие авиакомпании с освоением новых типов ВС и новых линий - очевидный фактор риска авиационного события, в авиакомпании «Трансаэро»с использованием АС УРПП построен рейтинг освоенных аэродромов по риску выхода за эксплуатационные ограничения по перегрузке на посадке и по углу тангажа на взлете и посадке.

\section{Заключение}

Таким образом, разработанная технология прогностического оценивания функциональной надёжности пилота, реализованная в АС УРПП, позволяет реализовать индивидуальное априорное оценивание риска авиационного события (инцидента) по группе причинных факторов «экипаж» на наиболее ответственных этапах полета (на взлете и посадке) до того, как будет накоплена статистика авиационных событий, обусловленных выходом пилотажных параметров за эксплуатационные ограничения, что имеет важное значение для обеспечения превентивного управления уровнем безопасности полетов в авиакомпании, а также может использоваться в интересах оптимизации управления функционированием любых эргатических систем. 


\section{Тренды и управление 1(9) • 2015}

\section{Библиография}

1. Ушаков И.Б., Богомолов А.В., Кукушкин Ю.А. Методологические аспекты динамического контроля функциональных состояний операторов опасных профессий // Медико-биологические и социально-психологические проблемы безопасности в чрезвычайных ситуациях. 2010. № 4-2. С. 6-12.

2. Гузий А.Г., Кукушкин Ю.А., Богомолов А.В., Пономаренко А.В., Федоров М.В., Щербаков С.А. Технология синтеза интегральных показателей функционального состояния членов летного экипажа // Проблемы безопасности полетов. 2007. № 1. С. 52-68.

3. Ушаков И.Б., Кукушкин Ю.А., Богомолов А.В., Карпов В.Н. Потенциальная ненадежность действий оператора как характеристика степени влияния физико-химических факторов условий деятельности // Безопасность жизнедеятельности. 2001. № 1. С. 24-29.

4. Кукушкин Ю.А., Богомолов А.В., Гузий А.Г. Методология стабилизации функционального состояния оператора системы “человек-машина” // Мехатроника, автоматизация, управление. 2002. №5. С. 9 - 14.

5. Ушаков И.Б., Богомолов А.В., Кукушкин Ю.А. Принципы организации контроля и оптимизации функционального состояния операторов // Безопасность жизнедеятельности. 2006. № 1. C. 4-10.

6. Kukushkin Yu.A., Bogomolov A.V. Procedure for synthesizing the index of an operator's psychophysiological stress // Медицинская техника. 2001. № 4. С. 29-33.

7. Богомолов А.В. Концепция математического обеспечения диагностики состояния человека // Информатика и системы управления. 2008. № 2 (16). С. 11-13.

8. Ушаков И.Б., Богомолов А.В., Кукушкин Ю.А. Психофизиологические механизмы формирования и развития функциональных состояний // Российский физиологический журнал им. И.М. Сеченова. 2014. Т. 100. № 10. С. 1130-1137.

9. Дворников М.В., Кукушкин Ю.А., Богомолов А.В., Матюшев Т.В. Технология синтеза законов управления человеко-машинными системами, эксплуатируемыми в условиях высокого риска гипоксических состояний человека // Двойные технологии. 2014. № 1 (66). С. 8-11.

10. Ушаков И.Б., Богомолов А.В. Информатизация программ персонифицированной адаптационной медицины // Вестник Российской академии медицинских наук. 2014. № 5-6. С. 124-128.

11. Ушаков И.Б., Богомолов А.В., Кукушкин Ю.А. Физиология труда и надежность деятельности человека. Под ред. А.И. Григорьева. М.: Наука. 2008. 318 с.

12. Ушаков И.Б., Богомолов А.В., Кукушкин Ю.А. Паттерны функциональных состояний оператора. М.: Наука. 2010. $390 \mathrm{c}$

13. Богомолов А.В., Гридин Л.А., Кукушкин Ю.А., Ушаков И.Б. Диагностика состояния человека: математические подходы. М.: Медицина. 2003. 464 с.

14. Максимов И.Б., Столяр В.П., Богомолов А.В. Прикладная теория информационного обеспечения медикобиологических исследований. М.: Бином. 2013. 312 с.

15. Ушаков И.Б., Богомолов А.В., Гридин Л.А., Кукушкин Ю.А. Методологические подходы к диагностике и оптимизации функционального состояния специалистов операторского профиля. М.: Медицина, 2004. $144 \mathrm{c}$.

16. Кукушкин Ю.А., Богомолов А.В., Гузий А.Г. Принципы построения системы обеспечения жизнедеятельности операторов систем “человек-машина”, адаптивных к их функциональному состоянию // Мехатроника, автоматизация, управление. 2005. № 3. С. 50-55.

17. Гузий А.Г., Богомолов А.В., Кукушкин Ю.А. Теоретические основы функционально-адаптивного управления системами “человек-машина" повышенной аварийности // Мехатроника, автоматизация, управление. 2005. № 1. С. 39-44.

18. Правила расследования авиационных происшествий и инцидентов с гражданскими воздушными судами в Российской Федерации. - М.: Авиаиздат, 1998. - 140 с.

19. Кибардин Ю.А. Использование методов математической статистики в задачах обеспечения безопасности полетов. - М.: ВВИА им. Н.Е. Жуковского, 1989. - 48 с. 


\section{Человеческий фактор}

20. Базлев Д.А., Евдокименков В.Н., Красильщиков М.Н. Построение характеристических множеств для индивидуально-адаптированной поддержки летчика при выполнении типовых полетных режимов // Известия РАН. Теория и системы управления. 2008, №4, с. 97-108.

21. Гузий А.Г. Методологический подход к управлению риском выхода параметров полета за эксплуатационные ограничения / Труды общества независимых расследователей авиационных происшествий (Выпуск 21). - М., 2009. С. 213-221.

22. Гумбель Э. Статистическая теория экстремальных значений / Введение в теорию порядковых статистик. - М.: Статистика, 1970. С. 61 - 93.

23. Рудаков И.С., Рудаков С.В., Богомолов А.В. Методика идентификации вида закона распределения параметров при проведения контроля состояния сложных систем // Информационно-измерительные и управляющие системы. 2007. Т. 5. № 1. С. 66-72.

24. Вентцель Е.С. Теория вероятностей: Учеб. для вузов. - 8-е изд., стер. - М.: Высшая школа, 2002. 280 с.

25. Гузий А.Г., Лушкин А.М. Методологический подход к формированию корпоративной стратегии управления безопасностью полетов // Проблемы безопасности полетов. № 9, 2008. С. 3-9.

26. Чжоу Ичжи Оптимизация работы экипажа в кабине в Китае: угрозы и исправление ошибок / Краткое содержание выступлений и докладов на 57-м международном семинаре Всемирного Фонда Безопасности Полетов (15 -18 ноября 2004 г.), Шанхай, КНР. - М.: «Некоммерческое партнерство «Безопасность полетов», 2004.

27. Гузий А.Г., Лушкин А.М., Щеглов И.Н., Софийский Д.В. Автоматизация процедур количественного оценивания риска выхода за эксплуатационные ограничения в полете./ Разработка и внедрение корпоративной системы управления безопасностью полетов. Материалы открытой научно-практической конференции авиакомпании «ТРАНСАЭРО» 23 октября 2008 года / Под ред. А.Г. Гузия. М., 2009. С. 76-79.

28. Гузий А.Г., Лушкин А.М., Щеглов И.Н., Софийский Д.В. Автоматизированная система управления рисками при производстве полетов (АС УРПП). - Свидетельство о регистрации программ для ЭВМ № 2009614485 от 21.08.2009 - Федеральная служба по интеллектуальной собственности и товарным знакам, 2009.

\section{References (transliterated)}

1. Ushakov I.B., Bogomolov A.V., Kukushkin Yu.A. Metodologicheskie aspekty dinamicheskogo kontrolya funktsional'nykh sostoyanii operatorov opasnykh professii // Mediko-biologicheskie i sotsial'no-psikhologicheskie problemy bezopasnosti v chrezvychainykh situatsiyakh. 2010. № 4-2. S. 6-12.

2. Guzii A.G., Kukushkin Yu.A., Bogomolov A.V., Ponomarenko A.V., Fedorov M.V., Shcherbakov S.A. Tekhnologiya sinteza integral'nykh pokazatelei funktsional'nogo sostoyaniya chlenov letnogo ekipazha // Problemy bezopasnosti poletov. 2007. № 1. S. 52-68.

3. Ushakov I.B., Kukushkin Yu.A., Bogomolov A.V., Karpov V.N. Potentsial'naya nenadezhnost' deistvii operatora kak kharakteristika stepeni vliyaniya fiziko-khimicheskikh faktorov uslovii deyatel'nosti // Bezopasnost' zhiznedeyatel'nosti. 2001. № 1. S. 24-29.

4. Kukushkin Yu.A., Bogomolov A.V., Guzii A.G. Metodologiya stabilizatsii funktsional'nogo sostoyaniya operatora sistemy "chelovek-mashina" // Mekhatronika, avtomatizatsiya, upravlenie. 2002. №5. S. 9 - 14.

5. Ushakov I.B., Bogomolov A.V., Kukushkin Yu.A. Printsipy organizatsii kontrolya i optimizatsii funktsional'nogo sostoyaniya operatorov // Bezopasnost' zhiznedeyatel’nosti. 2006. № 1. S. 4-10.

6. Kukushkin Yu.A., Bogomolov A.V. Procedure for synthesizing the index of an operator's psychophysiological stress // Meditsinskaya tekhnika. 2001. № 4. S. 29-33.

7. Bogomolov A.V. Kontseptsiya matematicheskogo obespecheniya diagnostiki sostoyaniya cheloveka // Informatika i sistemy upravleniya. 2008. № 2 (16). S. 11-13.

8. Ushakov I.B., Bogomolov A.V., Kukushkin Yu.A. Psikhofiziologicheskie mekhanizmy formirovaniya i razvitiya funktsional'nykh sostoyanii // Rossiiskii fiziologicheskii zhurnal im. I.M. Sechenova. 2014. T. 100. № 10. S. 1130-1137.

DOI: 10.7256/2307-9118.2015.1.14117 


\section{Тренды и управление 1(9) • 2015}

9. Dvornikov M.V., Kukushkin Yu.A., Bogomolov A.V., Matyushev T.V. Tekhnologiya sinteza zakonov upravleniya cheloveko-mashinnymi sistemami, ekspluatiruemymi v usloviyakh vysokogo riska gipoksicheskikh sostoyanii cheloveka // Dvoinye tekhnologii. 2014. № 1 (66). S. 8-11.

10. Ushakov I.B., Bogomolov A.V. Informatizatsiya programm personifitsirovannoi adaptatsionnoi meditsiny // Vestnik Rossiiskoi akademii meditsinskikh nauk. 2014. № 5-6. S. 124-128.

11. Ushakov I.B., Bogomolov A.V., Kukushkin Yu.A. Fiziologiya truda i nadezhnost' deyatel'nosti cheloveka. Pod red. A.I. Grigor'eva. M.: Nauka. 2008. 318 s.

12. Ushakov I.B., Bogomolov A.V., Kukushkin Yu.A. Patterny funktsional'nykh sostoyanii operatora. M.: Nauka. 2010. $390 \mathrm{~s}$

13. Bogomolov A.V., Gridin L.A., Kukushkin Yu.A., Ushakov I.B. Diagnostika sostoyaniya cheloveka: matematicheskie podkhody. M.: Meditsina. 2003. $464 \mathrm{~s}$.

14. Maksimov I.B., Stolyar V.P., Bogomolov A.V. Prikladnaya teoriya informatsionnogo obespecheniya medikobiologicheskikh issledovanii. M.: Binom. 2013. $312 \mathrm{s.}$

15. Ushakov I.B., Bogomolov A.V., Gridin L.A., Kukushkin Yu.A. Metodologicheskie podkhody k diagnostike i optimizatsii funktsional'nogo sostoyaniya spetsialistov operatorskogo profilya. M.: Meditsina, 2004. $144 \mathrm{~s}$.

16. Kukushkin Yu.A., Bogomolov A.V., Guzii A.G. Printsipy postroeniya sistemy obespecheniya zhiznedeyatel'nosti operatorov sistem "chelovek-mashina", adaptivnykh k ikh funktsional'nomu sostoyaniyu // Mekhatronika, avtomatizatsiya, upravlenie. 2005. № 3. S. 50-55.

17. Guzii A.G., Bogomolov A.V., Kukushkin Yu.A. Teoreticheskie osnovy funktsional'no-adaptivnogo upravleniya sistemami "chelovek-mashina" povyshennoi avariinosti // Mekhatronika, avtomatizatsiya, upravlenie. 2005. № 1 . S. 39-44.

18. Pravila rassledovaniya aviatsionnykh proisshestvii i intsidentov s grazhdanskimi vozdushnymi sudami $v$ Rossiiskoi Federatsii. - M.: Aviaizdat, 1998. - 140 s.

19. Kibardin Yu.A. Ispol'zovanie metodov matematicheskoi statistiki $v$ zadachakh obespecheniya bezopasnosti poletov. - M.: VVIA im. N.E. Zhukovskogo, 1989. - 48 s.

20. Bazlev D.A., Evdokimenkov V.N., Krasil'shchikov M.N. Postroenie kharakteristicheskikh mnozhestv dlya individual'no-adaptirovannoi podderzhki letchika pri vypolnenii tipovykh poletnykh rezhimov // Izvestiya RAN. Teoriya i sistemy upravleniya. 2008, №4, s. 97-108.

21. Guzii A.G. Metodologicheskii podkhod k upravleniyu riskom vykhoda parametrov poleta za ekspluatatsionnye ogranicheniya / Trudy obshchestva nezavisimykh rassledovatelei aviatsionnykh proisshestvii (Vypusk 21). - M., 2009. S. 213-221.

22. Gumbel' E. Statisticheskaya teoriya ekstremal'nykh znachenii / Vvedenie v teoriyu poryadkovykh statistik. - M.: Statistika, 1970. S. 61 - 93.

23. Rudakov I.S., Rudakov S.V., Bogomolov A.V. Metodika identifikatsii vida zakona raspredeleniya parametrov pri provedeniya kontrolya sostoyaniya slozhnykh sistem // Informatsionno-izmeritel'nye i upravlyayushchie sistemy. 2007. T. 5. № 1. S. 66-72.

24. Venttsel' E.S. Teoriya veroyatnostei: Ucheb. dlya vuzov. - 8-e izd., ster. - M.: Vysshaya shkola, 2002. 280 s.

25. Guzii A.G., Lushkin A.M. Metodologicheskii podkhod k formirovaniyu korporativnoi strategii upravleniya bezopasnost'yu poletov // Problemy bezopasnosti poletov. № 9, 2008. S. 3-9.

26. Chzhou Ichzhi Optimizatsiya raboty ekipazha v kabine v Kitae: ugrozy i ispravlenie oshibok / Kratkoe soderzhanie vystuplenii i dokladov na 57-m mezhdunarodnom seminare Vsemirnogo Fonda Bezopasnosti Poletov (15 -18 noyabrya 2004 g.), Shankhai, KNR. - M.: «Nekommercheskoe partnerstvo «Bezopasnost' poletov», 2004.

27. Guzii A.G., Lushkin A.M., Shcheglov I.N., Sofiiskii D.V. Avtomatizatsiya protsedur kolichestvennogo otsenivaniya riska vykhoda za ekspluatatsionnye ogranicheniya v polete./ Razrabotka i vnedrenie korporativnoi sistemy upravleniya bezopasnost'yu poletov. Materialy otkrytoi nauchno-prakticheskoi konferentsii aviakompanii «TRANSAER0» 23 oktyabrya 2008 goda / Pod red. A.G. Guziya. M., 2009. S. 76-79.

28. Guzii A.G., Lushkin A.M., Shcheglov I.N., Sofiiskii D.V. Avtomatizirovannaya sistema upravleniya riskami pri proizvodstve poletov (AS URPP). - Svidetel’stvo o registratsii programm dlya EVM № 2009614485 ot 21.08.2009 - Federal'naya sluzhba po intellektual'noi sobstvennosti i tovarnym znakam, 2009. 